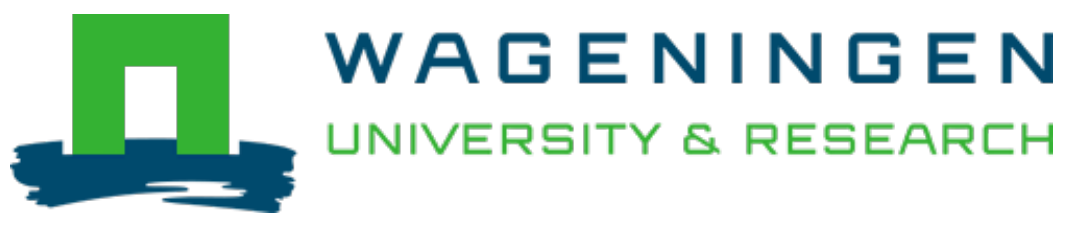

\title{
The influence of perceived benefits on acceptance of GM applications for allergy prevention
}

\author{
Health, Risk \& Society \\ Schenk, M.F.; Fischer, A.R.H.; Frewer, L.J.; Gilissen, L.J.W.J.; Jacobsen, E. et al \\ https://doi.org/10.1080/13698570802160947
}

This article is made publicly available in the institutional repository of Wageningen University and Research, under the terms of article $25 \mathrm{fa}$ of the Dutch Copyright Act, also known as the Amendment Taverne. This has been done with explicit consent by the author.

Article 25 fa states that the author of a short scientific work funded either wholly or partially by Dutch public funds is entitled to make that work publicly available for no consideration following a reasonable period of time after the work was first published, provided that clear reference is made to the source of the first publication of the work.

This publication is distributed under The Association of Universities in the Netherlands (VSNU) 'Article $25 \mathrm{fa}$ implementation' project. In this project research outputs of researchers employed by Dutch Universities that comply with the legal requirements of Article $25 \mathrm{fa}$ of the Dutch Copyright Act are distributed online and free of cost or other barriers in institutional repositories. Research outputs are distributed six months after their first online publication in the original published version and with proper attribution to the source of the original publication.

You are permitted to download and use the publication for personal purposes. All rights remain with the author(s) and / or copyright owner(s) of this work. Any use of the publication or parts of it other than authorised under article $25 \mathrm{fa}$ of the Dutch Copyright act is prohibited. Wageningen University \& Research and the author(s) of this publication shall not be held responsible or liable for any damages resulting from your (re)use of this publication.

For questions regarding the public availability of this article please contact openscience.library@,wur.nl 
This article was downloaded by: [Wageningen UR Library]

On: 20 June 2011

Access details: Access Details: [subscription number 907218144]

Publisher Routledge

Informa Ltd Registered in England and Wales Registered Number: 1072954 Registered office: Mortimer House, 3741 Mortimer Street, London W1T 3JH, UK

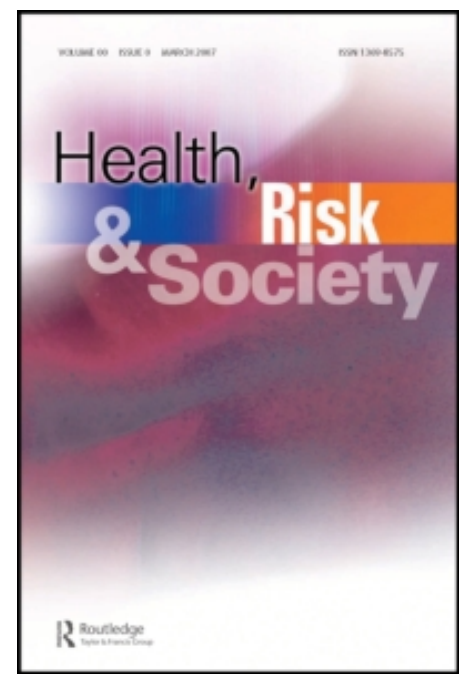

\section{Health, Risk \& Society}

Publication details, including instructions for authors and subscription information:

http://www.informaworld.com/smpp/title content=t713424479

\section{The influence of perceived benefits on acceptance of GM applications for} allergy prevention

M. F. Schenk ${ }^{\text {ab }}$; A. R. H. Fischerc; L. J. Frewer ${ }^{\text {ac }}$ L. J. W. J. Gilissen ${ }^{\text {ab. E. Jacobsen }}{ }^{\text {d }}$; M. J. M. Smulders ${ }^{\text {ab }}$ ${ }^{a}$ Allergy Consortium, Wageningen, The Netherlands ${ }^{b}$ Plant Research International, Wageningen, The Netherlands ${ }^{c}$ Department of Marketing and Consumer Behaviour, Wageningen, The Netherlands ${ }^{\mathrm{d}}$ Laboratory of Plant Breeding, Wageningen, The Netherlands

To cite this Article Schenk, M. F. , Fischer, A. R. H. , Frewer, L. J., Gilissen, L. J. W. J. , Jacobsen, E. and Smulders, M. J. M.(2008) 'The influence of perceived benefits on acceptance of GM applications for allergy prevention', Health, Risk \& Society, 10: 3, $263-282$

To link to this Article: DOI: $10.1080 / 13698570802160947$

URL: http://dx.doi.org/10.1080/13698570802160947

\section{PLEASE SCROLL DOWN FOR ARTICLE}

\footnotetext{
Full terms and conditions of use: http://www.informaworld.com/terms-and-conditions-of-access.pdf

This article may be used for research, teaching and private study purposes. Any substantial or systematic reproduction, re-distribution, re-selling, loan or sub-licensing, systematic supply or distribution in any form to anyone is expressly forbidden.

The publisher does not give any warranty express or implied or make any representation that the contents will be complete or accurate or up to date. The accuracy of any instructions, formulae and drug doses

should be independently verified with primary sources. The publisher shall not be liable for any loss, actions, claims, proceedings, demand or costs or damages whatsoever or howsoever caused arising directly or indirectly in connection with or arising out of the use of this material.
} 


\title{
The influence of perceived benefits on acceptance of GM applications for allergy prevention
}

\author{
M.F. Schenk ${ }^{\mathrm{a}, \mathrm{b}}$, A.R.H. Fischer ${ }^{\mathrm{c}}$, L.J. Frewer ${ }^{\mathrm{a}, \mathrm{c}}$, L.J.W.J. Gilissen ${ }^{\mathrm{a}, \mathrm{b}}$, \\ E. Jacobsen ${ }^{\mathrm{d}}$ and M.J.M. Smulders ${ }^{\mathrm{a}, \mathrm{b}}$ \\ ${ }^{a}$ Allergy Consortium, Wageningen, The Netherlands, ${ }^{b}$ Plant Research International, Wageningen, The \\ Netherlands; ${ }^{c}$ Department of Marketing and Consumer Behaviour, Wageningen, The Netherlands; \\ ${ }^{d}$ Laboratory of Plant Breeding, Wageningen, The Netherlands
}

(Received 15 June 2007; final version received 23 January 2008)

\begin{abstract}
Allergic diseases, such as hay fever and food allergy, affect an increasing part of the population in Westernized countries and have a negative impact on the patient's quality of life. Allergy prevention measures that focus on reducing the allergenic load are currently developed, and these may include the use of genetic modification of allergenic plants. Such developments should take societal concerns about genetic modification into account. We examined the attitude of allergic and non-allergic respondents towards applications of genetic modification for allergy prevention in one food allergy application (apple) and two hay fever applications (birch, grass). Attitude towards genetic modification was described in terms of 'benefits' and 'rejection factors.' We found that respondents suffering from self-reported allergy perceived greater benefits associated with the birch application as compared to non-sufferers. The perceived benefits increased with an increasing impact of allergic complaints on quality of life. No differences were found between sufferers and non-sufferers for the food allergy application. The impact of perceived benefits on acceptance was larger than that of rejection factors. This supports the idea that acceptance of genetic modification is primarily a function of perceived personal benefit. Novel genetically modified products that are perceived to be beneficial by some consumers may consequently experience an increased consumer acceptance.
\end{abstract}

Keywords: allergy prevention; genetic modification; GM societal acceptance

\section{Introduction}

\section{Allergy and societal issues}

Allergic diseases affect a substantial proportion of the population in Westernized countries (Strachan 1989, Aberg et al. 1995, Wuthrich et al. 1995). Evidence suggests that the prevalence of allergy has increased during recent decades. Seasonal allergic rhinitis (hay fever) can be caused by various types of pollen. It is the most common allergic disease and affects between $11 \%$ and $19 \%$ of the population in Western European countries (UCB institute of Allergy 1997). It may act as a precursor to allergic asthma (Meltzer 2001). In addition, sufferers that have been sensitized to birch pollen are particularly prone to develop oral allergy syndrome due to IgE-mediated cross-reactivity between pollen allergens and food proteins (Wensing et al. 2002, Ferreira et al. 2004). Approximately

*Corresponding author. Email: Martijn.Schenk@wur.nl 
$50-70 \%$ of the birch allergic sufferers display symptoms upon the ingestion of fruits and vegetables, including apple, cherry, celery and carrot (Fritsch et al. 1998, Bohle et al. 2003, Ferreira et al. 2004).

Sufferers experience symptoms such as sneezing, rhinorrhea and itchy eyes upon exposure to allergenic pollen. Hay fever is accompanied by fatigue, irritated glands and loss of sleep and of concentration (Meltzer 2001). Oral allergy syndrome leads to an itchy or burning sensation of the palate, rarely combined with mucosal swelling, angioedema, nausea or rhinitis symptoms. The oral allergy syndrome is generally not life threatening, but does have a negative impact upon quality of life. Quality of life assessments can be used to quantify the impact of hay fever and oral allergy syndrome on daily life from the patient's perspective, and to determine the need for social, emotional and physical support (Sicherer et al. 2001). Annual costs for allergic rhinitis add up to an estimated $€ 3$ billion in Europe (UCB Institute of Allergy 1997). A lack of information has limited the quantification of the socio-economic impact for food allergies (Miles et al. 2005). Development of effective allergy prevention strategies is likely to have a positive impact on socio-economic factors for both individual sufferers and society in general.

\section{Prevention of hay fever and food allergy}

Treatment of hay fever focuses mainly on the mitigation of allergic symptoms through administration of medication (UCB institute of Allergy 1997). Long-term treatment for various pollen allergies may be achieved by immunotherapy for some sufferers. The burden for sufferers is relatively high, given that immunotherapy takes a long time and that its eventual success is uncertain. Allergy prevention comprises any intervention that leads to a reduced sensitization to allergens (primary prevention) or to a reduced occurrence of allergic complaints (secondary prevention). Sufferers who have developed hay fever may limit the occurrence of symptoms by avoiding contact with allergenic pollen, for example by minimizing contact with outdoor air during periods with high pollen concentrations.

The primary preventive measure used for oral allergy syndrome is avoidance, which can be achieved by dietary exclusion of allergenic foods and, if necessary, any products derived from it. Full dietary exclusion is not necessary when the food is tolerated in a processed form. Dietary exclusion requires measures that facilitate consumer choice in the retail environment, such as communication and end-point labelling (Mills et al. 2004, Van Putten et al. 2006). Poor labelling, as well as so-called precautionary labelling, might lead to unnecessary restrictions in the diet of allergic individuals and their families (Hourihane 2001, McCabe et al. 2001). Therefore, avoidance of food allergens imposes restrictions on social activities and potentially has a severe impact on the life of sufferers and that of their family (Fernandez-Rivas and Miles 2004).

Alternative prevention measures may focus on plants or on products that provoke allergic reactions. In the case of hay fever, varieties with a reduced allergen content of the pollen or a reduced amount of pollen may be selected within the natural range of variation. Likewise, apple varieties differ in allergenicity and several cultivars contain low levels of allergens (Bolhaar et al. 2005). Selective breeding may further enhance such characteristics. Selection for such traits is however time-consuming and complicated. Currently, safety assessments are an important tool to ensure the safety of novel genetically modified crops (Taylor 2003). Assessments take into account the unintended introduction of allergens in these crops (Goodman et al. 2005), but genetic modification may actually aid in the development of hypoallergenic plants or foods from existing 
varieties. Examples are hypoallergenic ryegrass (Bhalla et al. 1999, Petrovska et al. 2005), apple (Gilissen et al. 2005) or soybean (Herman et al. 2003). Whichever approach is used to reduce allergy problems, the examples of previous technological innovations in the food chain, such as food irradiation and first generation GMO's in Europe, imply that its success or failure is contingent on societal acceptance of both products and processes.

\section{Societal issues in relation to genetic modification}

Societal concerns about aspects connected to genetic modification should be taken into account when replacing allergenic products with hypoallergenic counterparts using genetic modification. Such considerations are most useful at the initiation of product development. Public perceptions and attitudes towards new technologies are important factors for successful development and implementation of such technologies. DNA research has generally been perceived as an unknown and moderately dreaded hazard in the past (Slovic 1987), resulting in adverse reactions from the public towards genetic modification. Many debates about the implementation of genetic modification were instigated from the early 1990s onwards, following the introduction of first generation applications of genetic modification. Public support for genetically modified food in Europe has declined between 1996 and 1999, slightly increased between 1999 and 2002, and declined again between 2002 and 2005, although the attitude varied among European countries (Gaskell et al. 2006). Conversely, support for medical applications of modern biotechnology remains high. Societal acceptance likely depends on both overall public attitudes towards genetic modification technology and on public responses to specific applications. As a result, the public is inclined to accept or reject different applications of this technology on a case-by-case basis (Frewer et al. 1997).

Generally, genetic modification of plants or microorganisms is more acceptable than genetic modification of animals (Zechendorf 1994, Frewer et al. 1997), although acceptance also varies considerably within these categories. Applications of genetic modification can be divided into three major categories. The majority of the European consumers are positive about 'red' medical genetic modification, reject the 'green' agricultural genetic modification, and are indifferent to 'white' industrial genetic modification. Medical applications tend to be considered more necessary, and thereby more acceptable, than food-related applications (Zechendorf 1994, Frewer et al. 1997). Evidence suggests that consumer acceptance of genetically modified foods is driven by recognition of specific and personally relevant benefits, and by the perception that consumers, rather than industry, will benefit from a particular application (Miles and Frewer 2001). Demographic variables, such as age, gender, social class, education and attitudes towards the environment are also known to influence the attitude towards genetic modification (Siegrist 1998, Titchener and Sapp 2002).

\section{Research aims}

The research presented here examines and models the attitudes of consumers towards the use of genetic modification for allergy prevention. Two hay fever applications (birch, grass) and one food allergy application (apple) were included in the study. A survey methodology was applied to data collection. Given that people's attitude towards genetic modification partly depends on perceptions of personal risk and benefit, it is hypothesized that genetically modified products that result in a reduced occurrence of allergic reactions will be more positively received by allergic sufferers. In turn, acceptance is expected to 
increase with an increasing severity of allergic complaints experienced by individual sufferers.

All examined applications of genetic modification can be considered medical in nature due to their relation with allergy prevention. In addition, the hay fever applications may be associated with environmental concerns due to the distribution of pollen into the environment, while the apple application is associated with food-related concerns. Given the strong impact of food-related concerns on consumer perceptions (Frewer 2000), we expect the apple application to be rated more negatively than the applications in birch and grass.

\section{Methods}

\section{Main survey}

The survey investigated attitudes towards the use of genetic modification for allergy prevention for three applications, namely apple, birch and grass. Grass and birch are the main provokers of hay fever in the Netherlands. At the same time, they represent pollen sources of different size and different distribution pattern. Apple allergy is connected to birch allergy due to cross-reactions between the major birch allergens Bet v 1 and Bet v 2 and the homologues proteins Mald 1 and Mald 4 in apple (Wensing et al. 2002). Apple is a major allergenic food. It generally causes relatively mild allergic symptoms, which makes it more comparable to hay fever than, for example, a life-threatening peanut allergy would be. One exception is apple allergy caused by a lipid transfer protein (Mal d 3), which may result in severe symptoms (Pastorello et al. 1999). In recent years, research has been conducted towards development of genetically modified hypoallergenic apples (Gilissen et al. 2005), hypoallergenic rye grass (Bhalla et al. 1999, Petrovska et al. 2005) and birch trees that do not flower (Lemmetyinen et al. 2004).

The main survey was carried out in 2005. Increased publicity about allergies is likely during the hay fever period, and hay fever sufferers are actually experiencing symptoms at that time. As the timing of the survey might influence the response, the sample was split into two. A total of 282 respondents received the questionnaire prior to the birch hay fever season (mid-February) and 250 respondents during the birch hay fever season (first week of May). The timing of the survey was included as an independent variable in the multivariate analysis.

Data were collected using quota sampling in order to obtain a representative sample. The quota variables were age, gender and region of the Netherlands where the respondent lived. A professional social research company conducted the survey through an online questionnaire. Respondents were assigned to one of three quota blocks: (A) 178 respondents for the birch and grass application, (B) 179 respondents for the birch and apple application, and (C) 175 respondents for the grass and apple application. No significant differences were observed for demographic and allergy characteristics between the three quota groups (A, B and C). The order of the items was randomized within each block of questions.

\section{Pilot study and survey design}

A pilot survey was conducted, comprising two phases. The first phase was used to reduce the number of items and to test their comprehensibility. Survey items were primarily developed from existing literature. The pilot questionnaire was made available online, and completed by a convenience sample of 72 Dutch respondents. Items that provided no 
additional information were removed to reduce questionnaire length. For pragmatic considerations regarding respondent fatigue, each respondent was asked to answer items on two out of three cases. This further reduced the number of items from 119 to 94 per respondent. For the second phase of the pilot, a social research company selected a sample of 60 Dutch respondents and conducted the pilot through an online questionnaire. In this phase, findings from the first phase were confirmed for the more representative sample and open issues were resolved. Based on these results, an anchored 7-point scale was chosen and the option 'don't know' was removed. No further adaptations were made.

\section{Attitude items}

The survey items regarding attitude towards genetic modification were derived from previous research on acceptance of specific applications of genetic modification (Frewer et al. 1997). The original scale included 17 items. Given the health-related nature of our applications, two items on health effects were added. These were 'please indicate to what extent you think that the use of genetic modification will have negative health effects' and 'please indicate to what extent you think that the use of genetic modification will have positive health effects.' Principal components analysis was applied to identify underlying factors in the data set, reflecting sets of items that measured the same attitudinal construct. The set of 19 items was reduced to 14 (see Table 3) after application of this analysis in the pilot study. Responses were collected on 7-point scales anchored by 'not at all' and 'to a large extent.' The three applications were introduced by a brief explanation (see Appendix), ensuring that all respondents were answering questions after being given the same amount of information about hay fever and food allergy.

\section{Prevention strategy items}

Five prevention strategies which could potentially mitigate the occurrence of symptoms due to birch pollen allergy in the urban environment were presented. The strategies might also add to primary prevention, but we will focus on the effects of secondary prevention, because of the distinction between sufferers and non-sufferers made throughout this paper. The first strategy was directed towards allergy sufferers and focused on prevention of birch pollen allergy through 'avoiding contact with pollen.' Three strategies were directed towards replacement of allergenic trees with either 'other tree species,' 'other birch varieties that have been selected from existing varieties for a reduced allergenicity' or 'genetically modified birch trees that have been altered to have a reduced allergenicity.' To allow a comparison with the current situation, 'maintaining the current situation' was included as a fifth option. The same strategies were presented for grass. The first prevention strategy with regard to apple consumption focused on 'avoiding contact with apples.' The other strategies were directed towards replacement of allergenic apples with either 'other fruits,' or 'other apples that have been selected from existing varieties for their reduced allergenicity' or 'genetically modified apples that have been altered to have a reduced allergenicity.' The fifth option was 'maintaining the current situation.' Respondents were asked to indicate to what extent they found it desirable to implement a particular strategy. Responses were collected on 7-point scales anchored by 'highly undesirable' and 'highly desirable.' The desirability of implementing the strategy that involved genetic modification was used to measure acceptance of genetic modification for allergy prevention and was used as a dependent variable in the multivariate analysis. 


\section{Allergy and demographic items}

Respondents were asked to indicate whether they suffered from any allergic disorders. For allergic respondents, information was collected regarding the type of allergic disorder (allergic rhinitis, food allergy, allergic eczema, allergic asthma, and insect sting, medication and metal allergy), the (recent) use of medication, allergy diagnosis, timing of the symptoms, and substances to which they were allergic. Items on quality of life were included for hay fever sufferers to assess the severity of their complaints. The 14 quality of life items were developed and validated in previous research on adults suffering from rhino-conjunctivitis (Juniper and Guyatt 1991, Juniper et al. 2000). Currently, there is no validated method available to measure quality of life for food allergy sufferers. The frequent occurrence of hay fever and food allergy in the Netherlands allowed us to use a random population sample to include a sufficiently large group of allergy sufferers in the study.

Selected demographic characteristics were recorded (age, gender, household composition, education level, income, urbanization and employment). Four items measured the selfreported overall health of the respondents. Items that were intended to explain individual differences in general concern over the environment were included. Responses were collected on anchored 7-point scales (see Appendix for items and anchors). Acceptance of genetically modified hypoallergenic products was modelled in terms of the attitudinal components derived from the survey on attitude towards specific applications of genetic modification, and in terms of the demographic characteristics included in the survey.

\section{Results}

\section{Sample demographics}

The demographic characteristics of the respondent sample are provided in Table 1.

Table 1. Demographic description of the study population.

\begin{tabular}{lc}
\hline & Number of respondents \\
\hline$N$ & 532 \\
Gender & \\
Male & $266(50 \%)$ \\
Female & $266(50 \%)$ \\
Age: Mean $(S D)$ & $43.9(12.6)$ \\
Household composition & \\
Single & $76(17 \%)$ \\
Single with kids & $19(4 \%)$ \\
Partner & $134(30 \%)$ \\
Partner with kids & $184(41 \%)$ \\
Other & $40(9 \%)$ \\
Education & \\
$6-10$ years & $125(30 \%)$ \\
$11-14$ years & $176(42 \%)$ \\
$15-17$ years & $121(29 \%)$ \\
Income & \\
Below modal & $72(19 \%)$ \\
About modal & $109(29 \%)$ \\
About 1.5 times modal & $93(25 \%)$ \\
About 2 times modal & $59(16 \%)$ \\
About 2.5 times modal or more & $40(11 \%)$ \\
\hline
\end{tabular}

${ }^{1}$ Modal house hold income in the Netherlands was about €29.000 in 2005. 
There was an equal distribution of missing demographic information between sufferers and non-sufferers. No differences were found between sufferers and nonsufferers with respect to education $\left(\chi^{2}=3.37\right.$, df $\left.2, p=0.19\right)$, income $\left(\chi^{2}=6.21, d f 4\right.$, $p=0.18)$, and household composition $\left(\chi^{2}=3.52\right.$, df $\left.4, p=0.48\right)$. However, the distribution of sufferers differed significantly with respect to age and gender. The average age of sufferers was $41.9(S D=12.2)$, which was significantly lower than the average age of non-sufferers $(45.7, S D=12.6)(F(1,530)=12.28, p<0.001)$. This is in concordance with allergy prevalence data from cross-sectional studies for the adult population, which have reported a decreasing prevalence of allergic sensitization with increasing age (UCB Institute of Allergy 1997). The prevalence of self-reported allergic complaints was higher among women $\left(\chi^{2}=6.80\right.$, $\left.d f 1, p<0.01\right)$ of whom $54 \%$ reported allergic complaints, while $41 \%$ of the males reported these. Women are known to report higher allergy prevalence when self-reported allergic diseases are concerned (Knibb et al. 1999, Fagan et al. 2001, Marklund et al. 2004). Women often perceive higher risks than men do (Finucane et al. 2000), which may partially account for this difference in health reporting behaviour.

The study population was also characterized according to the allergy background of the respondents (Table 2). Forty seven percent of the respondents indicated that they suffered from allergic complaints. This seems higher than the average of $35 \%$ of the population commonly reported in research using diagnostic tools to detect elevated levels of specific IgE, such as skin-prick tests or blood tests (UCB Institute of Allergy 1997). This can partly be explained by allergy sufferers being more willing to respond to a questionnaire about allergies, causing a self-selection bias. In addition, self-report data tend to indicate higher prevalence estimates than those based on diagnosis by health professionals, due to an imperfect distinction between atopic and non-atopic symptoms (Marklund et al. 2004). Please note that in the remainder of this paper, the distinction between allergy sufferers and non-sufferers is based on self-reported allergy. This may lead, of course, to misclassification of individuals who suffer from food intolerances or true (non-allergic) rhinitis symptoms as sufferers. However, as perceived allergy is likely to influence attitude independent on whether a formal allergy diagnosis has been made, this

Table 2. Self-reported allergy background of the respondents according to the type of allergy and the allergens to which sufferers are sensitized.

Number of respondents

Allergy $(N=532)$

Non-allergic

Allergic

$284(53 \%)$

Type of allergy among allergy sufferers $(n=248)$

Only allergic rhinitis

Only food allergy

Both allergic rhinitis and food allergy

Other allergies

$248(47 \%)$

Allergen sensitization among allergy sufferers $(n=248)$

Only pollen allergens

Only fruit/nut allergens

$110(44 \%)$

$21(8 \%)$

$39(16 \%)$

$78(31 \%)$

Both pollen and fruit/nut allergens

$95(38 \%)$

$9(4 \%)$

Other allergens

$27(11 \%)$

Unknown allergens

$57(23 \%)$

$60(24 \%)$ 
misclassification is unlikely to influence whether or not individuals accept products with a reduced allergenicity.

The majority of self-reported allergic complaints concerned allergic rhinitis $(70 \%)$. Food allergy was reported frequently in combination with allergic rhinitis (Table 2). Allergy sufferers can also be characterized according to the allergens which they perceive to induce an allergic reaction. We distinguished between pollen, fruit and/or nuts, other, and unknown allergens. Given the large number of sufferers that were pollen allergic without knowing the exact source, and the large overlap between both groups $(52 \%$ of the sufferers allergic to pollen were allergic to both grass and tree pollen), no distinction was made between tree and grass pollen allergies. Overall, the largest group of respondents were allergic to pollen allergens $(49 \%)$, while a smaller but still substantial percentage $(24 \%)$ did not know the source of their allergy. There was a large overlap between pollen and fruit/nut allergic groups $(17 \%)$, which is expected given the occurrence of crossreactions between pollen allergens and food allergens.

\section{Attitude subscales}

A principal component analysis was applied to determine the number of dimensions of the attitude items. The responses towards the item 'personal objections' did not show a normal distribution. This item was therefore excluded from the analysis. The analysis (Varimax rotated) was first performed separately for the three applications (birch, grass and apple). The results indicated a two-factor solution for each application, based on Eigenvalues larger than one. The Eigenvalues of the first two components were 6.24 and 1.74 for the birch application. The next component had an Eigenvalue of 0.91 . Results were similar for the grass application (Eigenvalues of $6.00,1.77$ and 0.89 ) and the apple application (Eigenvalues of 6.89, 1.73 and 0.98 ). The two factors explained a comparable amount of variance (cumulative $61 \%$ for birch, $65 \%$ for grass and $66 \%$ for apple), while items loaded onto the components in a similar fashion across each application. The combined dataset also indicated a two-factor solution, with the first two components having Eigenvalues of 6.53 and 1.77, while the third component had an Eigenvalue of 0.92. The rotated components respectively accounted for $40 \%$ and $24 \%$ of the variance. The dimensions, composed by the items that loaded onto each component, were treated as subscales (Table 3).

The ambivalent item 'long-term effects' did not load well on either component, and was excluded from further analysis.

The internal consistency of the remaining subscales was estimated using Cronbach's alpha. In other words, do all the items contribute to the measurement of the component under consideration? Alpha was respectively 0.92 and 0.85 for the two components, indicating good internal reliability. However, there is some criticism regarding Cronbach's alpha as a definitive test for construct reliability as it is, for example, vulnerable in the situation of colinearity. Confirmatory factor analysis (using LISREL) was applied to determine whether the number of factors and the loadings of measured (indicator) variables associated with them were in concordance with the original principal components analysis. The resulting model shows reasonable fit parameters $\left(\chi^{2}(53)=357\right.$, RMSEA $=0.075$, GFI $=0.95$, AGFI $=0.92$ and $\mathrm{CFI}=$ $0.98)^{1}$. This confirms the reliability of the constructs identified in the original principal components analysis. Based on the content of the items, the two sub-scales were interpreted as 'rejection factors' and 'benefits,' and were used as dependent variables in further analyses. 
Table 3. Principal Component Analysis loadings. Bold numbers indicate which variables load on a principal component ${ }^{1}$.

\begin{tabular}{lcr}
\hline & \multicolumn{2}{c}{ Component } \\
\cline { 2 - 3 } & Rejection factors & Benefits \\
\hline Risky & $\mathbf{0 . 8 2}$ & -0.20 \\
Damaging & $\mathbf{0 . 8 0}$ & -0.24 \\
Personal worries & $\mathbf{0 . 8 0}$ & -0.18 \\
Tampering with nature & $\mathbf{0 . 8 0}$ & -0.27 \\
Unethical & $\mathbf{0 . 7 9}$ & -0.18 \\
Unnatural & $\mathbf{0 . 7 9}$ & -0.16 \\
Negative health effects & $\mathbf{0 . 7 6}$ & -0.26 \\
Long-term effects ${ }^{2}$ & 0.43 & 0.42 \\
Progressive & 0.03 & $\mathbf{0 . 5 9}$ \\
Positive health effects & -0.40 & $\mathbf{0 . 6 6}$ \\
Beneficial & -0.42 & $\mathbf{0 . 7 6}$ \\
Necessary & -0.34 & $\mathbf{0 . 7 8}$ \\
Important & -0.39 & $\mathbf{0 . 7 9}$ \\
\hline
\end{tabular}

${ }^{1}$ The item 'personal objections' was removed because the responses deviated from a normal distribution.

${ }^{2}$ The ambiguous item 'long term effects' contributed to neither factors and was excluded from further analysis.

\section{Differences between food allergy and hay fever applications}

The survey covered genetic modification of two hay fever and one food allergy application. A straightforward comparison of the 'application' effect was not possible due to the balanced incomplete block design. We adjusted for block effects by calculating the average score for each quota group and subtracting this score from the individual responses. Sufferers were defined here as being food allergic and/or pollen allergic, while non-sufferers were defined as being neither food allergic nor pollen allergic. This definition allowed a simultaneous comparison of 'sufferer' and 'application' effects. A multivariate analysis of variance (MANOVA) was applied in order to assess group differences across the different dependent variables simultaneously. Specifically, differences between attitudes towards benefits and rejection factors were tested between the different applications as well as between allergy suffers and non-allergy suffers (Pillai's trace $F(4,2116)=5.99, p<0.001$ ). The univariate tests revealed that all differences accrued to the benefits $(F(5,1058)=5.93$, $p<0.001)$ and not to the rejection factors $(F(5,1061)=2.09, p=0.06)$. The subsequent ANOVA on the benefits was significant for the 'application' variable $(F(2,1061)=21.81$, $p<0.001)$, the 'sufferer' variable $(F(1,1062)=7.30, p<0.05)$, and there was a significant 'application' $\times$ 'sufferer' interaction $(F(2,1061)=7.38, p<0.05)$. A post hoc Tukey test $(p<0.05)$ revealed that the hay fever applications were perceived significantly more beneficial than the apple application, but were not different from each other. The interaction effect shows that the increased perception of benefits for these applications is fully attributable to the larger perceived benefits by allergy sufferers, since no differences between applications were found for non-sufferers (Figure 1).

\section{Attitude and acceptance of allergy sufferers and non-sufferers}

The benefits of having genetically modified hypoallergenic products available are not equal for all members of the population. Only people who have an allergic reaction to particular product variants experience a direct benefit from the hypoallergenic counterpart. The 


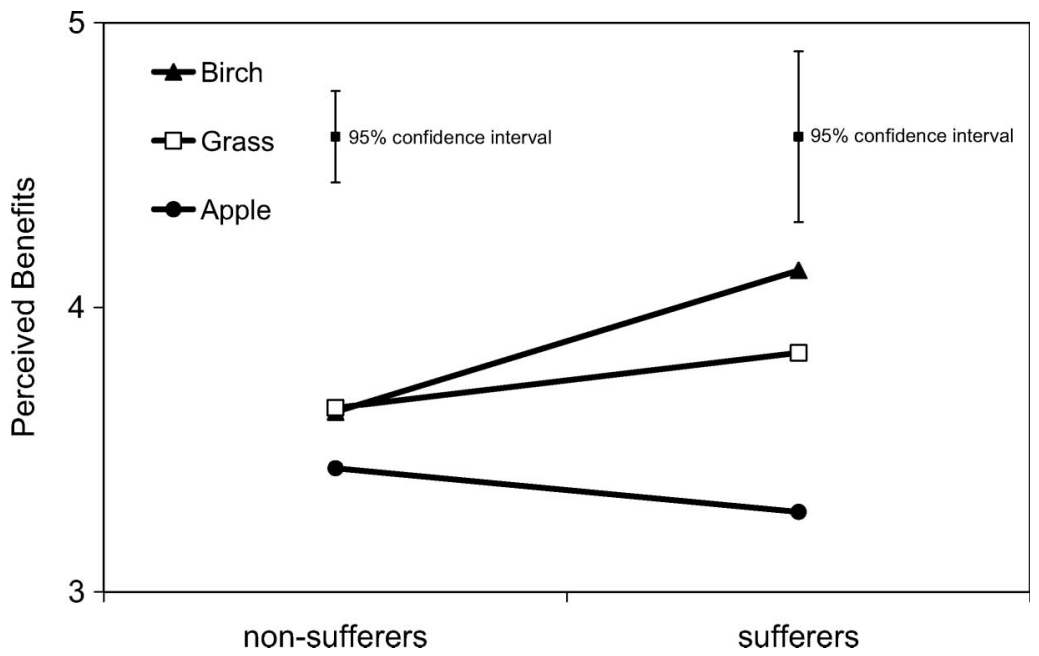

Figure 1. Mean item scores and 95\% confidence interval of the attitude component 'benefits' separated for the three applications, and for allergic sufferers and non-sufferers. Allergic sufferers are defined as respondents with a self-diagnosed pollen and/or food allergy.

distinction between sufferers and non-sufferers was, therefore, case-dependent. Sufferers were categorized as 'pollen allergic respondents' for the hay fever applications $(n=122)$ and as 'food allergic respondents' for the apple application $(n=60)$. Forty-three foodallergic respondents were part of the quota blocks that included items on apple. Given the small group size of food allergic respondents, we randomly selected 43 respondents from the remaining respondents when testing for attitude differences between sufferers and nonsufferers in relation to the apple application.

The attitude towards genetic modification for allergy prevention was influenced by whether the respondent suffered from allergy. There was a significant multivariate effect (MANOVA) of self-reported pollen/food allergy on the variables benefits and rejection factors for the birch application (Pillai's trace $F(2,354)=9.46, p<0.001$ ). However, such differences were neither found for grass (Pillai's trace $F(2,350)=1.15, p=0.32$ ) nor for apple (Pillai's trace $F(2,83)=0.43, p=0.65$ ). A subsequent ANOVA for the birch application revealed a significant difference between sufferers and non-sufferers for the benefits $(F(1,355)=15.95, p<0.001)$, but not for the rejection factors $(F(1,355)=0.76$, $p=0.38)$. Pollen allergic sufferers perceived greater benefits of the use of genetic modification than non-sufferers (Table 4).

We also investigated the attitude of allergic respondents that were neither pollen nor food allergic. No significant attitude differences were found between this group and the non-allergic respondents with regard to the proposed genetically modified plants (birch: Pillai's trace $F(2,262)=0.65, p=0.65$; grass: Pillai's trace grass $F(2,276)=0.84$, $p=0.43$; apple: Pillai's trace $F(2,308)=0.17, p=0.85)$. This confirms the expectation that direct personal benefits play a significant role in acceptance. Therefore, the classification of sufferers as respondents with a self-diagnosed pollen allergy or food allergy was maintained throughout this paper.

A MANOVA was used to examine differences in acceptance of prevention strategies between sufferers and non-sufferers. There was a significant multivariate effect of selfreported pollen allergy for the birch application (Pillai's trace $F(5,351)=6.06$, $p<0.001)$. Significant differences between sufferers and non-sufferers were found for 
Table 4. Mean item scores (standard deviation) ${ }^{1}$ of the attitude components and prevention strategy ratings separated for allergic sufferers and non-sufferers. The applications are tested separately because the patient group is case-dependent; sufferers are defined as pollen allergic for the hay fever applications, and as food allergic for the apple application.

\begin{tabular}{|c|c|c|c|c|c|c|}
\hline & \multicolumn{2}{|c|}{ Birch } & \multicolumn{2}{|c|}{ Grass } & \multicolumn{2}{|c|}{ Apple } \\
\hline & $\begin{array}{l}\text { Non- } \\
\text { sufferers } \\
n=265\end{array}$ & $\begin{array}{l}\text { Sufferers } \\
n=92\end{array}$ & $\begin{array}{l}\text { Non- } \\
\text { sufferers } \\
n=279\end{array}$ & $\begin{array}{c}\text { Sufferers } \\
n=74\end{array}$ & $\begin{array}{l}\text { Non- } \\
\text { sufferers } \\
n=311\end{array}$ & $\begin{array}{l}\text { Sufferers } \\
n=43\end{array}$ \\
\hline \multicolumn{7}{|l|}{ Attitude characteristics } \\
\hline $\begin{array}{l}\text { Rejection } \\
\text { factors }\end{array}$ & $4.17(1.47)$ & $4.01(1.62)$ & $4.30(1.54)$ & $4.12(1.63)$ & $4.38(1.55)$ & $4.62(1.78)$ \\
\hline $\begin{array}{l}\text { Benefits } \\
\text { Prevention strategy }{ }^{2}\end{array}$ & $3.61(1.30)$ & $4.26(1.44)$ & $3.64(1.34)$ & $3.91(1.49)$ & $3.41(1.30)$ & $3.27(1.27)$ \\
\hline Avoid contact & $4.78(1.49)^{\mathrm{a}}$ & $5.22(1.49)^{\mathrm{a}}$ & $4.67(1.57)^{\mathrm{a}}$ & $4.81(1.59)^{\mathrm{a}}$ & $4.62(1.87)^{\mathrm{a}}$ & $4.95(1.90)^{\mathrm{a}}$ \\
\hline $\begin{array}{l}\text { Replacement } \\
\text { with other } \\
\text { products }\end{array}$ & $4.82(1.51)^{\mathrm{a}}$ & $5.37(1.28)^{\mathrm{a}}$ & $4.54(1.54)^{\mathrm{a}}$ & $4.78(1.50)^{\mathrm{a}}$ & $4.81(1.87)^{\mathrm{a}}$ & $5.09(2.01)^{\mathrm{a}}$ \\
\hline $\begin{array}{l}\text { Replacement with } \\
\text { classical breeding }\end{array}$ & $4.83(1.42)^{\mathrm{a}}$ & $5.09(1.44)^{\mathrm{a}}$ & $4.78(1.52)^{\mathrm{a}}$ & $4.92(1.44)^{\mathrm{a}}$ & $4.72(1.60)^{\mathrm{a}}$ & $5.09(1.62)^{\mathrm{a}}$ \\
\hline $\begin{array}{l}\text { Replacement with } \\
\text { genetic } \\
\text { modification }\end{array}$ & $3.36(1.73)^{b}$ & $4.29(1.80)^{\mathrm{b}}$ & $3.42(1.78)^{\mathrm{c}}$ & $3.69(1.80)^{\mathrm{b}}$ & $3.11(1.72)^{\mathrm{c}}$ & $2.72(1.67)^{\mathrm{c}}$ \\
\hline $\begin{array}{l}\text { Maintaining the } \\
\text { current situation }\end{array}$ & $3.67(1.47)^{\mathrm{b}}$ & $3.23(1.58)^{\mathrm{c}}$ & $3.82(1.56)^{\mathrm{b}}$ & $3.50(1.62)^{\mathrm{b}}$ & $4.11(1.46)^{\mathrm{b}}$ & $3.84(1.62)^{\mathrm{b}}$ \\
\hline
\end{tabular}

${ }^{1}$ High numbers indicate high ratings on attitude subscales and a high desirability of implementing the prevention strategy. Numbers in bold indicate significant differences between sufferers and non-sufferers.

${ }^{2}$ A one-way ANOVA with a post-hoc Tukey test was applied to assess significance between the prevention strategies. Prevention strategies with the same subscript were not significantly different at the $p<0.05$ level over other strategies in the same column.

the strategies avoidance of contact with birch pollen $(F(1,355)=5.75, p<0.05)$, replacement with other tree species $(F(1,355)=9.97, \quad p<0.01)$, replacement with genetically modified birch trees $(F(1,355)=19.55, p<0.001)$ and maintaining the current situation $(F(1,355)=5.87, p<0.05)$. Inspection of the means indicated that sufferers rated the use of genetic modification, avoidance of contact and replacement with other tree species as more desirable than non-sufferers, while rating maintaining of the current situation as less desirable (Table 4). The finding that sufferers rated the strategy that involves genetic modification higher than non-sufferers is in concordance with the attitudinal differences. We found no significant multivariate effect of self-reported pollen/ food allergy for the prevention strategies concerning apple (Pillai's trace $F(5,348)=1.70$, $p=0.14$ ) and grass (Pillai's trace $F(5,347)=0.71, p=0.62$ ).

\section{Attitude and severity of hay fever complaints}

This analysis indicates that suffering from a pollen allergy influences attitude towards genetic modification for allergy prevention, and acceptance of the prevention strategies. To investigate additional influences of the severity of allergic complaints on attitude and acceptance, we divided the sufferers using a median split on their quality of life scores for rhino-conjunctivitis (Juniper and Guyatt 1991, Juniper et al. 2000). Subsequently, a oneway ANOVA was used to examine differences between sufferers with a low and with a high impact of hay fever on quality of life (Table 5). 
Table 5. Mean item scores (standard deviation) ${ }^{1}$ of the attitude components and prevention strategy ratings for the hay fever applications. Median split was used to separate between hay fever sufferers with a low impact and a high impact of hay fever on quality of life scores.

\begin{tabular}{|c|c|c|c|c|}
\hline \multirow[b]{2}{*}{ Impact on quality of life } & \multicolumn{2}{|c|}{ Birch } & \multicolumn{2}{|c|}{ Grass } \\
\hline & Low & High & Low & High \\
\hline \multicolumn{5}{|l|}{ Attitude characteristics } \\
\hline Rejection factors & $3.98(1.55)$ & $4.11(1.72)$ & $4.03(1.61)$ & $4.23(1.80)$ \\
\hline Benefits & $3.84(1.48)$ & $4.52(1.43)$ & $3.76(1.48)$ & $4.26(1.55)$ \\
\hline \multicolumn{5}{|l|}{ Prevention strategy } \\
\hline Avoid contact & $4.83(1.54)$ & $5.37(1.45)$ & $4.59(1.70)$ & $5.16(1.38)$ \\
\hline Replacement with other products & $5.00(1.17)$ & $5.48(1.33)$ & $4.36(1.50)$ & $5.56(1.23)$ \\
\hline Replacement with classical breeding & $4.61(1.59)$ & $5.28(1.31)$ & $4.41(1.37)$ & $5.84(0.99)$ \\
\hline Replacement with genetic modification & $3.67(1.71)$ & $4.63(1.84)$ & $3.41(1.68)$ & $4.04(2.01)$ \\
\hline Maintaining the current situation & $3.44(1.46)$ & $3.09(1.62)$ & $3.87(1.74)$ & $2.88(1.45)$ \\
\hline
\end{tabular}

${ }^{1}$ High numbers indicate high ratings on attitude subscales and high desirability of implementing the prevention strategy. A one-way ANOVA was applied to assess significance between the groups. Numbers in bold indicate significant differences between 'high and low impact on quality of life' groups at the $p<0.05$ level.

In the birch case, we found significant differences between sufferers with a high and with a low impact of hay fever for the attitude component benefits $(F(1,80)=4.34$, $p<0.05)$. In concordance with this finding, significant differences were found for implementation of the strategies replacement with birch trees developed by genetic modification $(F(1,80)=5.89, p<0.05)$ and replacement with birch varieties developed by classical breeding $(F(1,80)=4.39, p<0.05)$. No significant differences were found for the other strategies. Inspection of the means indicated that sufferers with a high impact of hay fever on quality of life perceive higher benefits and a higher desirability of implementing these prevention strategies (Table 5). We also found significant differences for the grass application in the ratings of the strategies replacement with other grass species $(F(1,62)=11.25, p<0.001)$, replacement with grass varieties developed by classical breeding $(F(1,62)=20.37, \quad p<0.001)$ and maintaining of the current situation $(F(1,62)=5.63, p<0.05)$. No significant differences were found for the other strategies or the attitude components. A high impact of hay fever on quality of life lead to higher ratings of the replacement strategies and lower ratings for maintaining of the current situation lower (Table 5). A similar comparison could not be made for apple, since there is currently no standardized method available to measure the impact of oral allergy syndrome on quality of life.

\section{Self-reported allergy and other demographic variables}

To investigate the relevance of the above findings, we performed multiple regression analysis to test simultaneously the effects of several demographic variables (gender, age, worries about the environment, general health, timing of the survey, urbanization, income and self-reported allergy), and the effect of the attitudinal components (benefits, rejection factors) on the acceptance of genetically modified hypoallergenic products. The results for the birch application are shown in Figure 2.

The attitudinal components, rejection factors and benefits were negatively correlated $(r=-0.57, p<0.001)$. This means that the components were not independent of each other. We compensated for this effect using partial correlations when investigating the 


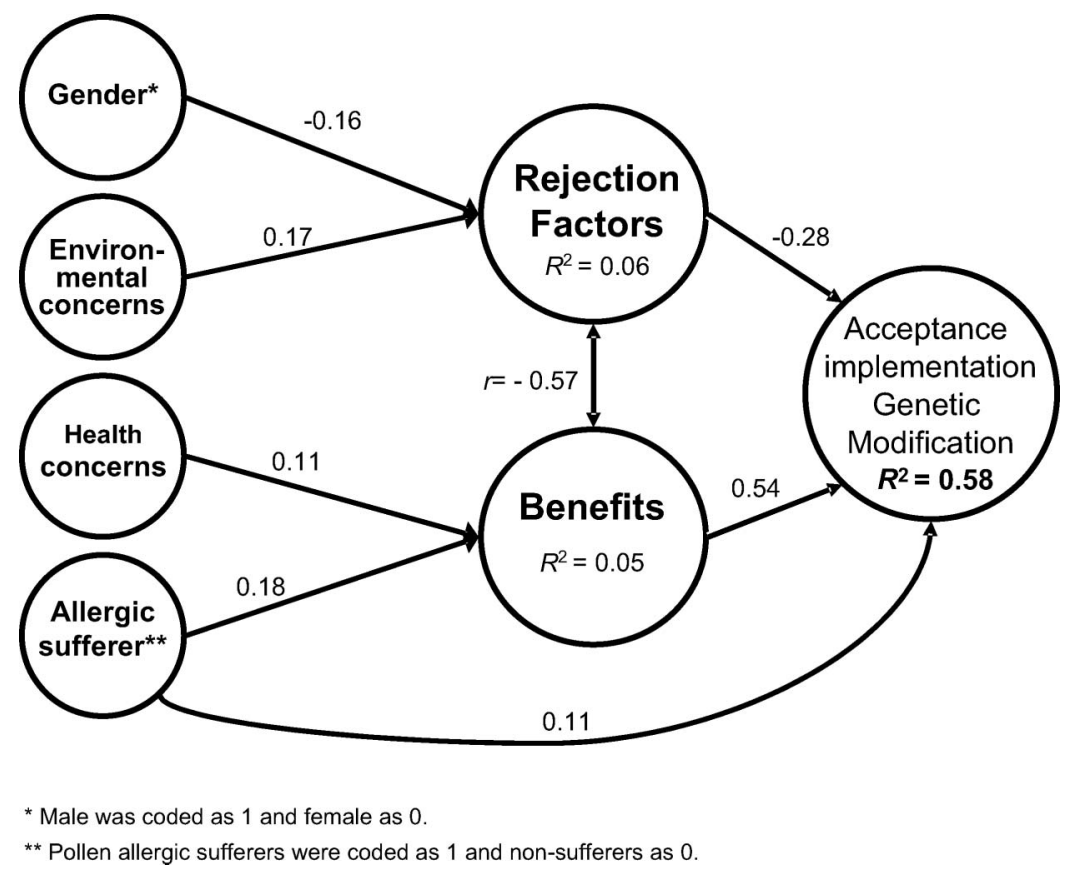

Figure 2. Multiple regression analysis for the use of genetic modification in birch for hay fever prevention. The acceptance of genetic modification is the ultimate dependent variable. The attitudinal components rejection factors and benefits were used as mediating variables. Demographic variables were used as independent variables. Significant $(p<0.05)$ relations are shown.

relation between attitudinal components and the significant demographic variables, such that the relation between 'worries about the environment' and benefits $(r=0.00$, $p=0.98$ ) was controlled for in the analysis. Thus, it can be concluded that the influence of environmental worries on benefit perception is fully mediated by perceived rejection factors. The variables 'worries about the environment' and gender had significant influences on the attitudinal component rejection factors $(F(2,354)=11.38, p<0.001$, $\left.R^{2}=0.06\right)$. Respondents who indicated more worries about the environment perceived more rejection factors associated with genetic modification $(F(1,355)=12.74, p<0.001$, $\left.R^{2}=0.03\right)$. Female respondents perceived more rejection factors than male respondents $\operatorname{did}\left(F(1,355)=11.75, p<0.001, R^{2}=0.03\right)$. The variables 'self-reported pollen allergy' and general health had a direct significant influence on the benefits component $\left(F(2,354)=10.00, p<0.001, R^{2}=0.05\right)$. Respondents who self-reported pollen allergy perceived more benefits associated with genetic modification of birch than those who were not $\left(F(1,355)=15.95, p<0.001, R^{2}=0.04\right)$. In addition, respondents who indicated a lower general health perceived more benefits $\left(F(1,355)=14.64, p<0.01, R^{2}=0.02\right)$.

The implementation of genetic modification for birch was used as dependent variable, while the measured attitudinal components (benefits and rejection factors) were used as independent variables. This analysis indicated that both benefits $(F(1,355)=384.16$, $\left.p<0.001, R^{2}=0.52\right)$ and rejection factors $\left(F(1,355)=189.97, p<0.001, R^{2}=0.35\right)$ had a significant (non-orthogonal) influence on acceptance. There was an additional effect of the demographic variable 'self-reported pollen allergy' on acceptance of genetic 
modification ( $p<0.01$, additional $R^{2}=0.01$ ). These non-orthogonal effects added up to a total explained variance of $58 \%$. Mediation analysis showed that the other demographic effects were fully mediated by either benefits or 'rejection factors,' with self-reported pollen allergy being only partially mediated by benefits (Figure 2).

A similar pattern of attitudinal variation for rejection factors emerged for the apple application $\left(F(2,351)=13.86, p<0.001, R^{2}=0.07\right)$ and in $\operatorname{grass}(F(1,351)=93.67$, $\left.p<0.001, R^{2}=0.11\right)$. The exception was the variable gender, which did not have a significant influence for the grass application. There were considerable differences for the 'benefits.' For grass, this variable was only slightly influenced by the health variable $\left(F(1,346)=4.52, p<0.05, R^{2}=0.01\right)$, while no significant predictors for benefits were found for apple. There was also no unmediated effect of the variable self-reported food allergy on acceptance of genetic modification. The benefits and rejection factors together did explain a similar amount of variation for all three applications (birch $F(3,353)=161.69, \quad p<0.001, \quad R^{2}=0.58 ; \quad$ apple $F(2,351)=226.51, \quad p<0.001$, $R^{2}=0.56$; grass $\left.F(2,350)=269.64, p<0.001, R^{2}=0.60\right)$.

\section{Implementation of prevention strategies}

To examine which strategies to prevent allergic symptoms are preferred by the respondents, we compared the ratings on desirability of implementing the different strategies. Given the observed differences in attitude between sufferers and non-sufferers, these groups were analysed separately by application of a one-way ANOVA. The prevention strategies had different levels of acceptance for the apple application (sufferers $F(4,210)=15.05, p<0.001$; non-sufferers $F(4,1550)=52.42, p<0.001$ ), birch (sufferers $F(4,430)=28.35, p<0.001$; non-sufferers $F(4,1345)=60.94, p<0.001)$ and grass (sufferers $F(4,335)=13.24, p<0.001$; non-sufferers $F(4,1420)=39.32, p<0.001$ ). A post-hoc Tukey test was conducted to examine which strategies differed from each other (Table 4). For all three applications, the strategies that focus on avoidance of contact, replacement with other products, and replacement with products developed by classical breeding scored significantly higher than replacement with products developed by genetic modification and maintaining the current situation (Table 4). Both sufferers and nonsufferers rated the use of genetic modification in apple (much) lower than maintaining the current situation. Sufferers rated genetic modification as more acceptable than maintaining the current situation for birch, while these strategies were rated equally acceptable by non-sufferers. Sufferers rated genetic modification of grass equally acceptable to maintaining the current situation, while non-sufferers were more negative about genetic modification (Table 4).

\section{Discussion}

\section{Attitude towards genetic modification}

The results in this study provided partial support for the hypothesis that allergy sufferers perceive genetically modified products that are hypoallergenic more positively than nonallergic people do. To find this confirmation, the attitude towards the use of genetic modification was measured on two subscales that were labelled as rejection factors and benefits. Hay fever sufferers perceived greater benefits associated with genetically modified birch compared to non-sufferers. No differences were observed between allergic and nonallergic groups in terms of perceived rejection factors. Although there was a tendency for sufferers to perceive greater benefits than non-sufferers for genetically modified grass, these 
differences were not significant. The differences are perhaps less pronounced for grass because this application is perceived as less realistic, at least in the Dutch context where grass is indigenous. This maybe different in, for example, Australia, where the development of transgenic hypoallergenic ryegrass is being evaluated (Petrovska et al. 2005). Replacement of birch in the urban environment by other trees or hypoallergenic birch trees certainly appears more feasible. Examining consumer attitudes in a country in which grass is not omnipresent in the environment may clarify this issue.

Besides a generic difference between sufferers and non-suffers of allergic complaints, it is further shown that the more severe the self-reported allergic complaints, the larger the perceived benefits and acceptance of genetically modified birch. As there is currently no method to assess quality of life in relation to the severity of apple allergy, these relations could only be investigated for hay fever (i.e. birch and grass).

Consumers perceive fewer benefits associated with the apple application, supporting the hypothesis that food allergy applications of genetic modification are rated more negatively than hay fever applications. This provides support for the idea that food related concerns are larger than many others are. More generally, this research confirms that the attitude towards use of genetic modification depends on the nature of the application (see also Zechendorf 1994, Frewer et al. 1997). Interestingly, all observed differences related to the perceived personal benefits. All three applications are partly medical in nature. In contrast, the apple application also relates to agriculture and food consumption, whereas the hay fever applications relate to environmental issues. This suggests that the apple application follows the broader pattern of societal resistance against food-related GMOs, whereas grass and birch are more in line with societally acceptable medical applications. It should also be noted that the food allergic group was more diverse in its food allergies compared to the hay fever sufferers, which may reduce the actually perceived personal benefit when specifically focusing on the example of apple. Given the sample, there were not enough respondents allergic to apple to conduct a separate analysis for this group. The lack of personal benefit for people with, for example, shrimp allergy, regarding their acceptance of genetically modified apples is obviously small, which may reduce acceptability of genetically modified apple. In future research we should take care that participants are the recipients of an actual and personally relevant benefit.

\section{Rejection factors, benefit and acceptance of GMOs}

Acceptance of genetically modified hypoallergenic products was modelled in terms of the two attitudinal components rejection factors and benefits, and the demographic characteristics. Frewer, Howard and Shepherd (1997) also found a two-dimensional attitudinal structure towards genetic modification. Both attitudinal components are also similar to the main variables in the model of gene technology acceptance proposed by Siegrist (2000), who indicated that the variables 'perceived benefit' and 'perceived risk' were influential in determining consumer acceptance. The perceived benefits of applying genetic modification to birch were mainly influenced by the perception that an individual is suffering from allergy, while for both hay fever applications it was also influenced by a person's perception of his/her health status. The strongest indicator of the rejection factors was a high level of environmental concern. This is in accordance with previous research by Siegrist (1998) who found that high levels of concern about the environment were one of the main predictors of general rejection of gene technology.

Benefits and rejection factors have a strong impact on acceptance of specific applications of genetic modification. We observed that differences in attitude both 
between sufferers and non-sufferers, and between different applications all relate to the perception of greater benefits but not to fewer rejection factors. This supports the idea that acceptance of genetically modified products is primarily a function of perceived personal benefit as opposed to personal or environmental risk perceptions per se. This is also indicated by the higher regression coefficient between perceived benefits and 'acceptance of genetic modification,' compared to the coefficient between rejection factors and 'acceptance of genetic modification' in Figure 2. Frewer (2003) concluded that as long as the risks are not as large as to be completely intolerable, an individual's acceptance would be driven by perceptions of personal benefit. A limitation of the study is that, although a fairly large fraction of the variance of acceptance of genetic modification could be explained based on general attitudes towards genetic modification, only a modest amount of this attitude can be explained from demographic and allergy characteristics. Future research should aim at identifying the variables that underlie the remaining fraction of the variance.

\section{Food allergy management and genetically modified products}

Van Putten et al. (2006) concluded that, in the context of novel foods, genetically modified products have the potential to contribute to food allergy management. However, the results of this study show a clear consumer preference for hypoallergenic apples grown by conventional breeding opposed to breeding by using genetic modification. Miles et al. (2005) found that a majority of food allergy sufferers would purchase low-allergen foods produced by genetic modification, but sufferers also expressed a clear preference for lowallergen foods produced by conventional breeding. We observed no differences between the attitudes of food allergy sufferers and non-sufferers towards genetically modified hypoallergenic apples. This may relate to the fact that apple allergy is relatively easy to manage by apple allergy sufferers themselves. The consequences of inadvertent exposure to apples are generally rather minor, and thus tolerable. The response might be different for food products that are harder to avoid or that provoke severe (anaphylactic) allergic reactions, such as peanut or peach. A second explanation might be that people suffering from food allergy or intolerances are more worried about technological food safety issues (Miles et al. 2004). A third explanation might be that the introduction of low-allergen products may complicate food allergy management for allergic consumers, who will not be able to discriminate between allergenic and non-allergenic products based on simple heuristic cues (do not eat apples) and on sensory selection criteria like smell or appearance. This would make avoidance of potentially allergenic foods more difficult, requiring an increased level of vigilance to the part of food allergic sufferers (Gowland 2001). The development of specialist niche markets, with explicit labelling protocols for low allergen products, may partially solve these problems.

Another difficulty is that hypoallergenic products that are non-allergenic for some sufferers might still be allergenic to others. Most allergenic foods contain a variety of food allergens, each with a different number of patients reacting to them. In a cost-effective development of hypoallergenic products, the focus will likely be on the major allergens. This implies that minor allergens will probably not be reduced in this process. Sufferers will also have individual threshold levels to particular allergens. Allergen reduction levels that suffice for one patient will not necessarily suffice for others, complicating matters further. As a result, some sufferers may still suffer from allergic complaints upon confrontation with acclaimed hypoallergenic foods. To avoid this, sufferers need detailed knowledge about which allergens affect them, and whether the hypoallergenic food still contain these specific 
allergens, rather than the more general knowledge about which products to avoid. Inadequate addressing of these issues may reduce trust in hypoallergenic foods.

A clear societal preference is shown for prevention strategies involving conventional breeding opposed to those involving genetic modification. In fact, the majority of the respondents prefer maintaining the current situation to the use of genetic modification for the apple and grass applications. The situation is more complicated for birch, since pollen allergic sufferers included in this study prefer the implementation of genetic modification to maintaining the current situation. Nineteen percent of the respondents included in the study preferred reduction of birch pollen allergens through genetic modification of birch when compared to conventional breeding approaches. In comparison, $47 \%$ of respondents preferred conventional breeding to genetic modification when applied to the objectives. Future research on hypoallergenic birch should, therefore, first explore the use of conventional breeding.

There is a trade-off between what the general public demands and what is currently feasible in terms of plant breeding perspectives. The use of conventional breeding techniques would be challenging and may require several decades to yield results, while the expression of the major apple allergen and ryegrass allergens have already been successfully reduced in transgenic plants by RNA interference or gene-silencing (Bhalla et al. 1999, Gilissen et al. 2005, Petrovska et al. 2005). The duration of the developing process was not, as such, included in this survey, but this factor raises the intriguing issue of what people would prefer, a GM solution now or a non-GM solution in several years or decades? Another issue to consider in future research is the attitude of the general public towards recent developments in the research field of plant breeding, such as cisgenic crops, in which no genetic material from foreign species is introduced during transformation (Schouten et al. 2006).

\section{Conclusion}

The attitude towards genetically modified products that have a reduced allergenicity compared to their conventional counterparts can be modelled in terms of benefits and rejection factors. The research reported shows that hay fever sufferers show higher acceptance levels towards hypoallergenic GM products compared to non-allergy sufferers. No differences were found in rejection factors. In other words, it is the perceived personal benefits associated with such products that account for the difference in an acceptance of novel applications between allergic and non-allergic individuals. Furthermore, the greater the perceived benefit the stronger is its positive effect on acceptance of the application. In the past, the emphasis of discussion about societal acceptance of different applications of genetic modification, whether health-related or otherwise, has tended to focus on the relation between perceived risk and acceptance. The research presented here underlines the importance of perceived personal benefits for consumer acceptance, independent of risk perceptions.

In the context of the introduction of other innovative technologies applied to health, it is possible that the effect reported here may have generic applicability, that is, acceptance or rejection of different technological applications may be primarily dependent on benefit perceptions, rather than on perceptions of risk. This topic merits further research in the future.

\section{Note}

Confirmatory factor analysis.

1. Fit measures for a structural equation model: RMSEA $<0.08$ is an indicator of acceptable fit. GFI, AGFI, CFI $>0.90$ are indicators of an acceptable fit; GFI, AGFI, CFI $>0.95$ are indicators of a good fit. 


\section{References}

Aberg, N., Hesselmar, B., Aberg, B., and Eriksson, B., 1995. Increase of asthma, allergic rhinitis and eczema in Swedish schoolchildren between 1979 and 1991. Clinical and experimental allergy, 25, 815-819.

Bhalla, P.L., Swoboda, I., and Singh, M.B., 1999. Antisense-mediated silencing of a gene encoding a major ryegrass pollen allergen. Proceedings of the national academy of science of the USA, 96, $11676-11680$.

Bohle, B., Radakovics, A., Jahn-Schmid, B., Hoffmann-Sommergruber, K., Fischer, G.F., and Ebner, C., 2003. Bet v 1, the major birch pollen allergen, initiates sensitization to Api g 1, the major allergen in celery: evidence at the T cell level. European journal of immunology, 33, 33033310.

Bolhaar, S.T.H.P., Van De Weg, W.E., Van Ree, R., Gonzalez-Macebo, E., Zuidmeer, L., Bruijnzeel-Koomen, C.A.F.M., et al., 2005. In vivo assessment with prick-to-prick testing and double-blind, placebo-controlled food challenge of allergenicity of apple cultivars. Journal of allergy and clinical immunology, 116, 1080-1086.

Fagan, J.K., Scheff, P.A., Hryhorczuk, D., Ramakrishnan, V., Ross, M., and Persky, V., 2001. Prevalence of asthma and other allergic diseases in an adolescent population: association with gender and race. Annals of allergy, asthma and immunology, 86, 77-184.

Fernandez-Rivas, M. and Miles, S., 2004. Food allergies: Clinical and psychosocial perspectives. In: E.N.C. Mills and P.R. Shewry, eds. Plant food allergies. Oxford: Blackwell, 1-23.

Ferreira, F., Hawranek, T., Gruber, P., Wopfner, N., and Mari, A., 2004. Allergic cross-reactivity: from gene to the clinic. Allergy, 59, 243-267.

Finucane, M.L., Slovic, P., Mertz, C.K., Flynn, J., and Satterfield, T.A., 2000. Gender, race, and perceived risk: the 'white male' effect. Health, risk \& society, 2, 159-172.

Frewer, L., 2000. Riskperception and risk communication about food safety issues. Nutrition bulletin, 25, 31-33.

Frewer, L., 2003. Societal issues and public attitudes towards genetically modified foods. Trends, food science \& technology, 14, 319-332.

Frewer, L., Howard, C., and Shepherd, R., 1997. Public concerns in the United Kingdom and specific applications of genetic engineering: risk, benefit, and ethics. Science, technology \& human values, 22, 98-124.

Fritsch, R., Bohle, B., Vollmann, U., Wiedermann, U., Jahn-Schmid, B., Krebitz, M., et al., 1998. Bet $\mathrm{v}$ 1, the major birch pollen allergen, and Mal d 1, the major apple allergen, cross-react at the level of allergen-specific T helper cells. Journal of allergy and clinical immunology, 102, 679686.

Gaskell, G., Allansdottir, A., Allum, N., Corchero, C., Fischler, C., Hampel, J., et al., 2006. Europeans and biotechnology in 2005: Patterns and trends, Eurobarometer 64.3. Available at http://ec.europa.eu/public_opinion/archives/eb_special_en.htm

Gilissen, L.J.W.J., Bolhaar, S.T.H., Matos, C.I., Rouweñdal, G.J.A., Boone, M.J., Krens, F.A., et al., 2005. Silencing the major apple allergen Mal d 1 by using the RNA interference approach. Journal of allergy and clinical immunology, 115, 364-369.

Goodman, R.E., Hefle, S.L., Taylor, S.L., and Van Ree, R., 2005. Assessing genetically modified crops to minimize the risk of increased food allergy: a review. International archives of allergy and immunology, 137, 153-166.

Gowland, M.H., 2001. Food allergen avoidance - the patient's viewpoint. Allergy, 56, 117-120.

Herman, E.M., Helm, R.M., Jung, R., and Kinney, A.J., 2003. Genetic modification removes an immunodominant allergen from soybean. Plant physiology, 132, 36-43.

Hourihane, J.O'B., 2001. The threshold concept in food safety and its applicability to food allergy. Allergy, 56, S86-S90.

Juniper, E.F. and Guyatt, G.H., 1991. Development and testing of a new measure of health-status for clinical-trials in Rhinoconjunctivitis. Clinical and experimental allergy, 21, 77-83.

Juniper, E.F., Thompson, A.K., Ferrie, P.J., and Roberts, J.N., 2000. Development and validation of the Mini Rhinoconjunctivitis Quality of Life Questionnaire. Clinical and experimental allergy, $30,132-140$.

Knibb, R.C., Armstrong, A., Booth, D.A., Platts, R.G., Booth, I.W., and Macdonald, A., 1999. Psychological characteristics of people with perceived food intolerance in a community sample. Journal of psychosomatic research, 47, 545-554. 
Lemmetyinen, J., Keikonen, K., and Sopanen, T., 2004. Prevention of the flowering of a tree, silver birch. Molecular breeding, 13, 243-249.

Marklund, B., Ahlstedt, S., and Nordström, G., 2004. Health-related quality of life among adolescents with allergy-like conditions - with emphasis on food hypersensitivity. Health and quality of life outcomes, 2, 65.

Mccabe, M., Lyons, R.A., Hodgeson, P., Griffiths, G., and Jones, R., 2001. Management of peanut allergy. Lancet, 357, 1531-1532.

Meltzer, E.O., 2001. Quality of life in adults and children with allergic rhinitis. Journal of allergy and clinical immunology, 108, S45-S53.

Miles, S. and Frewer, L.J., 2001. Investigating specific concerns about different food hazards. Food quality and preference, 12, 47-61.

Miles, S., Brennan, M., Kuznesof, S., Ness, M., Ritson, C., and Frewer, L.J., 2004. Public worry about specific food safety issues. British food journal, 106, 9-22.

Miles, S., Fordham, R., Mills, C., Valovirta, E., and Mugford, M., 2005. A framework for measuring costs to society of IgE-mediated food allergy. Allergy, 60, 996-1003.

Mills, E.N.C., Valovirta, E., Madsen, C., Taylor, S.L., Vieths, S., Anklam, E., et al., 2004. Information provision for allergic consumers - where are we going with food allergen labelling? Allergy, 59, 1262-1268.

Petrovska, N., Wu, X., Donato, R., Wang, Z., Ong, E.K., Jones, E., et al., 2005. Transgenic ryegrasses (Lolium spp.) with down-regulation of main pollen allergens. Molecular breeding, 14, 489-501.

Pastorello, E.A., Pravettoni, V., Farioli, L., Ispano, M., Fortunato, D., Monza, M., Giuffrida, M.G., Rivolta, F., Scibola, E., Ansaloni, R., Incorvaia, C., Conti, A., Ortolani, C. 1999. Clinical role of a lipid transfer protein that acts as a new apple - specific allergen. Journal of allergy and clinical immunology, 104, 1099-1106.

Schouten, H.J., Krens, F.A., and Jacobsen, E., 2006. Do cisgenic plants warrant less stringent oversight? Nature biotechnology, 24, 753.

Sicherer, S.H., Noone, S.A., and Muñoz-Furlong, A., 2001. The impact of childhood food allergy on quality of life. Annals of allergy, asthma and immunology, 87, 461-464.

Siegrist, M., 1998. Belief in gene technology: The influence of environmental attitudes and gender. Personality and individual differences, 24, 861-866.

Siegrist, M., 2000. The influence of trust and perceptions of risks and benefits on the acceptance of gene technology. Risk analysis, 20, 195-203.

Slovic, P., 1987. Perception of risk. Science, 236, 280-285.

Strachan, D.P., 1989. Hay-fever, hygiene, and household size. British medical journal, 299, 1259-1260.

Taylor, S.L., 2003. Safety assessment of foods produced through agricultural biotechnology. Nutrition reviews, 61, S135-S140.

Titchener, G.D. and Sapp, S.G., 2002. A comparison of two approaches to understanding consumer opinions of biotechnology. Social behavior and personality, 30, 373-381.

UCB Institute of Allergy, 1997. European allergy white paper. D. van Moerbeke, ed. Brussels: UCB.

Van Putten, M.C., Frewer, L.J., Gilissen, L.J.W.J., Gremmen, B., Peijnenburg, A.A.C.M., and Wichers, H.J., 2006. Novel foods and food allergies: A review of the issues. Trends in food science and technology, 17, 289-299.

Wensing, M., Akkerdaas, J.H., Van Leeuwen, A., Stapel, S.O., Bruijnzeel-Koomen, C.A.F.M., Aalberse, R.C., et al., 2002. IgE to Bet $\mathrm{v} 1$ and profilin: Cross-reactivity patterns and clinical relevance. Journal of allergy and clinical immunology, 110, 435-442.

Wuthrich, B., Schindler, C., Leuenberger, P., Ackermann-Liebrich, U., Alean, P., Blaser, K., et al., 1995. Prevalence of atopy and pollinosis in the adult-population of Switzerland (SAPALDIA study). International archives of allergy and immunology, 106, 149-156.

Zechendorf, B., 1994. What the public thinks about biotechnology. Better than synthetic food but worse than organ-transplantation. A survey of opinion polls. Biotechnology, 12, 870-875.

\section{Appendix}

\section{Introduction birch case}

'In the urban environment, birch trees are planted in gardens, parks and along streets. Birch trees produce pollen that causes hay fever complaints to a large number of people. This pollen may also cause allergic asthma and may be involved in the development of food allergy.' 


\section{Introduction grass case}

'In the urban environment grass is sown in lawns, parks and along streets. Grass produces pollen that causes hay fever complaints to a large number of people. This pollen may also cause allergic asthma.'

\section{Introduction apple case}

'Several hay fever sufferers develop a food allergy for particular fruits. An important example of this is apple allergy.'

\section{Health items and environment items}

Environment 1: Do you worry about the disappearance of natural areas (Never - Always)?

Environment 2: Do you worry about the disappearance of animal and plant species (Never Always)?

Environment 3: Do you worry about environmental pollution (Never - Always)?

Environment 4: Do you worry about global warming (Never - Always)?

Environment 5: Do you worry about sustainable use of energy recourses (Never - Always)?

Health 1: How would you describe your overall health (Very bad - Very good)?

Health 2: Are you ever hampered in your activities by your health in daily life (Always - Never)?

Health 3: Do you worry about your health (Always - Never)?

Health 4: If you compare your health with that of other people of the same age, do you feel (A lot worse - A lot better)?

The survey included four items on general health and five on worries about the environment. The internal consistency of these subscales was estimated using Cronbach's alpha and amounted 0.83 for the health items and 0.89 for the environment items. The means of the items were labelled as 'general health' and 'worries about the environment.' 